\title{
Study of factors affecting drug compliance in schizophrenia- cross sectional survey
}

\author{
Gopalan M.R ${ }^{1}$, Vidhu Kumar $\mathbf{K}^{2}$ \\ ${ }^{1}$ Dr Mohan Roy Gopalan, Assistant Professor, Department of Psychiatry, ${ }^{2}$ Karunakaran Vidhukumar, Additional \\ Professor, Department of Psychiatry, Government Medical College, Trivandrum Kerala, India.
}

Address for Correspondence: Dr Mohan Roy Gopalan, Email: drmohanroy@ gmail.com

\begin{abstract}
Introduction: Schizophrenia is a condition characterized by delusions, hallucinations, disorganized behavior, disorganized thought, and negative symptoms. There is overwhelming evidence that antipsychotics can be effective in treating the symptoms of schizophrenia. Approximately $75 \%$ of individuals relapse without drugs compared to $25 \%$ with drug. Patients who receive long-acting depot have lower relapse rates than patients who receive oral medications. The factors affecting drug compliance include side effects, psychopathology, social support, and insight. Indian studies are comparatively few in this area; knowledge of these factors can help in formulating strategies for enhancing drug compliance and outcome. Methods: This study was conducted at the Department of Psychiatry T D Medical College, Alleppey, a tertiary care teaching hospital. Patients who attended the Outpatient department were assessed with following instruments, Positive and negative symptom scale, Udvalg Klinske Undersogelser Side Effect Rating Scale, Multidimensional scale of perceived social support, Scale to assess Unawareness of Mental Disorder (SUMD), Compliance was assessed by using the criteria of fully compliant defined as those miss less than $20 \%$ of medication, partially compliant those who misses $20 \%$ to $80 \%$ of medication and noncompliant those who miss more than $80 \%$ of medicines. Data was analysed using Chi square test and regression analysis. Result: Sex, Education status, marital status, Occupation, and drugs administered had significant relationships with Compliance. Conclusion:, it is advisable to use minimum number of drugs for ensuring compliance.
\end{abstract}

Key words: Drug compliance, Schizophrenia, Delusions, Insight.

\section{Introduction}

Schizophrenia is a condition characterized by delusions, hallucinations, disorganized behavior, disorganized thought, and negative symptoms [1]. There is overwhelming evidence that antipsychotics can be effective in treating the symptoms of schizophrenia [2]. Approximately $75 \%$ of individuals relapse without drugs compared to $25 \%$ with drug. Patients who receive long-acting depot have lower relapse rates than patients who receive oral medications [3].

The factors affecting drug compliance include side effects, psychopathology, social support, and insight. Indian studies are comparatively few in this area; knowledge of these factors can help in formulating

Manuscript received $25^{\text {th }}$ May 2016

Reviewed: $10^{\text {th }}$ June 2016

Author Corrected: $20^{\text {th }}$ June 2016

Accepted for Publication $1^{\text {st } J u l y ~} 2016$ strategies for enhancing drug compliance and outcome.

Awareness of having an illness is associated with better medication compliance and better outcome [4]. Patient who live alone have low compliance rates than who live in supportive environment [5]. Side effects that occur early in treatment lead to a substantial reduction in compliance later [6)].

It is suggested that it may be possible to identify patients most likely to benefit from adherence intervention [7]. Knowledge of factors affecting drug compliance in schizophrenia is very vital in Indian scenario. But unfortunately studies in this area are less from this part of the world. This study aims to bridge this gap and tries to assess the drug compliance of patients taking antipsychotics. It also plans to assess the 
variables of recruited patients using appropriate rating instruments for Insight, severity of psychopathology, social support and side effects of medications and aims to study the interrelationship between these factors and drug compliance

Compliance is defined in many ways one of them is "compliance can be expressed as the ratio between an observed treatment behavior and given treatment standards" [8]. Definitions of compliance differ among different groups of workers, but it can be considered to be the degree to which a patient's behavior is consistent with medical advice [3].

The term adherence has been proposed as an alternative to compliance as it emphasizes the role of the patient as a collaborator in decisions regarding treatment. Study by Cramer and Rosenheck [9] reviewed studies of medication compliance for both psychiatric and medical illnesses.

The mean levels of compliance were $58 \%$ for antipsychotics, $65 \%$ for antidepressants and $76 \%$ for nonpsychiatric condition. Studies in arthritis and seizure disorders reviewed by Fenton and coworkers [10] have found higher rates of noncompliance.

\section{Materials and Methods}

Sample- This study was conducted at the Department of Psychiatry T D Medical College, Alleppey a tertiary care teaching hospital. Patients who attended the Outpatient department were the subjects for the study
The study was a cross sectional survey and following were the inclusion and exclusion criteria

\section{Inclusion criteria}

- Age 18 to 65

- Diagnosis of schizophrenia (D S M IV based)

- Patients living with at least one key relative who is available for interview

\section{Exclusion criteria}

- Patients who currently meet criteria for substance withdrawal

- Mental retardation

- Patients with Co morbid axis I disorder

Tools

- Compliance was defined at three levels in the following way

- Compliant-misses $<20 \%$ of medication

- Partially compliant- misses $20 \%$ to 80 of medication

- Noncompliant-misses $>80 \%$ of medication

- Positive and negative symptom scale ${ }^{11}$

- Udvalg Klinske Undersogelser Side Effect Rating Scale $^{12}$

- Multidimensional scale of perceived social support ${ }^{13}$

- Scale to assess Unawareness of Mental Disorder $(\mathrm{SUMD})^{14}$

Table1 represents relationship between sociodemographic factors and compliance it shows that females has significant compliance rates than males, compliance increasing with number of years of education, unmarried persons, Hindus and unemployed have more compliance rates.

Table 2 represents relationship between various illness factors and compliance. It shows that persons who has to spent between Rs. 51 and 100 has maximum compliance rates, analysing religious/alternate treatments and compliance rates it was found that people who doesn't go for alternate treatment has maximum compliance rates, analysing depot preparations and compliance rates it was found that people who take depot has less compliance compared to people who are not on depot, analysing the relationship between number of drugs administered and compliance it was found that persons with less number of medicines has more drug compliance then persons with more drugs.

Table 3 shows the relationship between symptom related factors and compliance. The relationship between positive symptoms and compliance showed that persons with average positive symptoms were more compliant compared to people with low positive symptom score, comparison of negative symptoms with compliance showed that people with average negative symptoms have more compliance rates compared to people with low negative symptom scores, comparing illness insight and compliance it was found that persons with low insight are more complaint compared to persons with high insight 


\section{Results}

Table-1: Sociodemographic Factors

\begin{tabular}{|c|c|c|c|c|c|}
\hline & \multicolumn{3}{|c|}{ Compliance (Score) } & \multirow{2}{*}{ Total } \\
\hline & & Non Compliant & Partially Compliant & Fully Compliant & \\
\hline \multirow{4}{*}{$\begin{array}{c}\text { Age } \\
\text { (years) }\end{array}$} & \multirow{2}{*}{$<50$} & 5 & 4 & 18 & 27 \\
\hline & & 18.51 & $44.40 \%$ & $58.10 \%$ & $54.00 \%$ \\
\hline & \multirow{2}{*}{$\geq 50$} & 5 & 5 & 13 & 23 \\
\hline & & $50.00 \%$ & $55.60 \%$ & $41.90 \%$ & $46.00 \%$ \\
\hline \multicolumn{6}{|c|}{ Chi square: $0.601 ; p>0.05$} \\
\hline \multirow{4}{*}{ Gender } & \multirow{2}{*}{ Male } & - & 5 & 9 & 14 \\
\hline & & & $35.71 \%$ & $64.28 \%$ & $100.00 \%$ \\
\hline & \multirow{2}{*}{ Female } & 10 & 4 & 22 & 36 \\
\hline & & $27.77 \%$ & $11.10 \%$ & $61.10 \%$ & $100.00 \%$ \\
\hline \multicolumn{6}{|c|}{ Chi square: $7.295 ; p<0.05$} \\
\hline \multirow{10}{*}{ Education } & \multirow{2}{*}{ SSLC } & 5 & - & 23 & 28 \\
\hline & & $50.00 \%$ & & $74.20 \%$ & $56.00 \%$ \\
\hline & \multirow{2}{*}{5 th Std } & - & 4 & 4 & 8 \\
\hline & & & $44.40 \%$ & $12.90 \%$ & $16.00 \%$ \\
\hline & \multirow{2}{*}{ 3rd Std } & 5 & - & - & 5 \\
\hline & & $50.00 \%$ & & & $10.00 \%$ \\
\hline & \multirow{2}{*}{ 2nd Std } & - & 5 & - & 5 \\
\hline & & & $55.60 \%$ & & $10.00 \%$ \\
\hline & \multirow{2}{*}{ Nil } & - & - & 4 & 4 \\
\hline & & & & $12.90 \%$ & $8.00 \%$ \\
\hline \multicolumn{6}{|c|}{ Chi square: $58.503 ; p<0.001$} \\
\hline \multirow{6}{*}{$\begin{array}{l}\text { Marital } \\
\text { Status }\end{array}$} & \multirow{2}{*}{ Married } & 10 & 5 & 5 & 20 \\
\hline & & $100 \%$ & $55.60 \%$ & $16.10 \%$ & $40.00 \%$ \\
\hline & \multirow{2}{*}{ Unmarried } & - & 4 & 22 & 26 \\
\hline & & & $44.40 \%$ & $71.00 \%$ & $52.00 \%$ \\
\hline & \multirow{2}{*}{$\begin{array}{c}\text { Widow/Widow } \\
\text { er }\end{array}$} & - & - & 4 & 4 \\
\hline & & & & $12.90 \%$ & $8.00 \%$ \\
\hline \multicolumn{6}{|c|}{ Chi square: $23.856 ; p<0.001$} \\
\hline \multirow{6}{*}{ Religion } & \multirow{2}{*}{ Hindu } & 5 & 4 & 17 & 26 \\
\hline & & $50.00 \%$ & $44.40 \%$ & $54.80 \%$ & $52.00 \%$ \\
\hline & \multirow{2}{*}{ Christian } & 5 & - & 9 & 14 \\
\hline & & $50.00 \%$ & & $29.00 \%$ & $28.00 \%$ \\
\hline & Muclim & - & 5 & 5 & 10 \\
\hline & IVIUSmII & & $55.60 \%$ & $16.10 \%$ & $20.00 \%$ \\
\hline Chi square & $2.336 ; p<0.05$ & & & & \\
\hline & Unomnloyed & 5 & 9 & 26 & 40 \\
\hline Occunation & Оiтетіріо уеа & $50.00 \%$ & $100 \%$ & $83.90 \%$ & $80.00 \%$ \\
\hline Onenation & Houcewife & 5 & - & 5 & 10 \\
\hline & HOUSEWIIE & $50.00 \%$ & & $16.10 \%$ & $20.00 \%$ \\
\hline Chi square & $8.165 ; p<0.05$ & & & & \\
\hline
\end{tabular}


Table 2: Illness Related Factors.

\begin{tabular}{|c|c|c|c|c|c|}
\hline & \multicolumn{3}{|c|}{ Compliance (Score) } & \multirow[b]{2}{*}{ Total } \\
\hline & & Non Compliant & $\begin{array}{c}\text { Partially } \\
\text { Compliant }\end{array}$ & $\begin{array}{c}\text { Fully } \\
\text { Compliant }\end{array}$ & \\
\hline \multirow{6}{*}{$\begin{array}{l}\text { Duration of } \\
\text { Illness }\end{array}$} & \multirow{2}{*}{$\leq 10$} & - & - & 13 & 13 \\
\hline & & & & $41.90 \%$ & $26.00 \%$ \\
\hline & \multirow{2}{*}{$11-20$} & 10 & - & 13 & 23 \\
\hline & & $100 \%$ & & $41.90 \%$ & $46.00 \%$ \\
\hline & \multirow{2}{*}{$>20$} & - & 9 & 5 & 14 \\
\hline & & & $100 \%$ & $16.10 \%$ & $28.00 \%$ \\
\hline \multicolumn{6}{|c|}{ Chi square: $39.581 ; p<0.001$} \\
\hline \multirow{6}{*}{$\begin{array}{l}\text { Duration of } \\
\text { Treatment }\end{array}$} & \multirow{2}{*}{$\leq 10$} & - & - & 13 & 13 \\
\hline & & & & $41.90 \%$ & $26.00 \%$ \\
\hline & \multirow{2}{*}{$11-20$} & 10 & 5 & 13 & 28 \\
\hline & & $100 \%$ & $55.60 \%$ & $41.90 \%$ & $56.00 \%$ \\
\hline & \multirow{2}{*}{$>20$} & - & 4 & 5 & 9 \\
\hline & & & $44.40 \%$ & $16.10 \%$ & $18.00 \%$ \\
\hline \multicolumn{6}{|c|}{ Chi square: $17.877 ; p<0.01$} \\
\hline \multirow{6}{*}{$\begin{array}{c}\text { Money } \\
\text { Expenditure } \\
\text { (Rs.) }\end{array}$} & \multirow{2}{*}{$\leq 50$} & 10 & 9 & 9 & 28 \\
\hline & & $100 \%$ & $100 \%$ & $29.00 \%$ & $56.00 \%$ \\
\hline & \multirow{2}{*}{$51-100$} & - & - & 18 & 18 \\
\hline & & & & $58.10 \%$ & $36.00 \%$ \\
\hline & \multirow{2}{*}{$\geq 101$} & - & - & 4 & 4 \\
\hline & & & & $12.90 \%$ & $8.00 \%$ \\
\hline \multicolumn{6}{|c|}{ Chi square: $24.078 ; p<0.001$} \\
\hline \multirow{6}{*}{$\begin{array}{c}\text { Other } \\
\text { Treatments }\end{array}$} & \multirow{2}{*}{ Religious } & - & 5 & 5 & 10 \\
\hline & & & $55.60 \%$ & $16.10 \%$ & $20.00 \%$ \\
\hline & \multirow{2}{*}{ Alternative } & - & - & 5 & 5 \\
\hline & & & & $16.10 \%$ & $10.00 \%$ \\
\hline & $\mathrm{Nil}$ & 10 & 4 & 21 & 35 \\
\hline & N1I & $100 \%$ & $44.40 \%$ & $67.70 \%$ & $70.00 \%$ \\
\hline Chisq & uare : $13.134 ; p<0.05$ & & & & \\
\hline & & 5 & 9 & 13 & 27 \\
\hline Depot & Yes & $50.00 \%$ & $100 \%$ & $41.90 \%$ & $54.00 \%$ \\
\hline Preparations & No & 5 & - & 18 & 23 \\
\hline & No & $50.00 \%$ & & $58.10 \%$ & $46.00 \%$ \\
\hline Chisg & uare : $9.548 ; p<0.01$ & & & & \\
\hline & Clozanine & 5 & - & 4 & 9 \\
\hline & Clozapine & $50.00 \%$ & & $12.90 \%$ & $18.00 \%$ \\
\hline & Olanzonine & - & - & 5 & 5 \\
\hline & Olanzapıne & & & $16.10 \%$ & $10.00 \%$ \\
\hline & & - & - & 13 & 13 \\
\hline & Risperidone + Depot & & & $41.90 \%$ & $26.00 \%$ \\
\hline & Donot \& Olonnoning & - & - & 4 & 4 \\
\hline Drugs & Depot + Olanzapıne & & & $12.90 \%$ & $8.00 \%$ \\
\hline administered & Risperidone + Clozapine + & - & - & 5 & 5 \\
\hline & Trihexyphenedyl & & & $16.10 \%$ & $10.00 \%$ \\
\hline & Risperidone + Depot + & - & 5 & - & 5 \\
\hline & Trihexyphenedyl & & $55.60 \%$ & & $10.00 \%$ \\
\hline & Risperidone + Soium & 5 & - & - & 5 \\
\hline & Valproate + Nitrazepam & $50.00 \%$ & & & $10.00 \%$ \\
\hline & Clozapine + Trihexyphenedyl & - & 4 & - & 4 \\
\hline & + Haloperidol & & $44.40 \%$ & & $8.00 \%$ \\
\hline Chisqu & are $: 85.305 ; p<0.001$ & & & & \\
\hline
\end{tabular}


Table-3: Symptom Related Factors.

\begin{tabular}{|c|c|c|c|c|c|}
\hline & & \multicolumn{3}{|c|}{ Compliance (Score) } & \multirow{2}{*}{ Total } \\
\hline & & Non Compliant & Partially Compliant & Fully Compliant & \\
\hline \multirow{4}{*}{$\begin{array}{c}\text { Positive } \\
\text { Symptoms }\end{array}$} & \multirow{2}{*}{ Low } & 10 & - & 13 & 23 \\
\hline & & $100 \%$ & & $41.90 \%$ & $46.00 \%$ \\
\hline & \multirow{2}{*}{ Average } & - & 9 & 18 & 27 \\
\hline & & & $100 \%$ & $58.10 \%$ & $54.00 \%$ \\
\hline \multicolumn{6}{|c|}{ Chi square: $19.612 ; p<0.001$} \\
\hline \multirow{4}{*}{$\begin{array}{c}\text { Negative } \\
\text { Symptoms }\end{array}$} & \multirow{2}{*}{ Low } & 5 & 5 & 5 & 15 \\
\hline & & $50.00 \%$ & $55.60 \%$ & $16.10 \%$ & $30.00 \%$ \\
\hline & \multirow{2}{*}{ Average } & 5 & 4 & 26 & 35 \\
\hline & & $50.00 \%$ & $44.40 \%$ & $83.90 \%$ & $70.00 \%$ \\
\hline \multicolumn{6}{|c|}{ Chi square: $7.544 ; p<0.05$} \\
\hline \multirow{4}{*}{ Insight } & \multirow{2}{*}{ Low $(<30 \%)$} & - & - & 14 & 14 \\
\hline & & & & $45.20 \%$ & $28.00 \%$ \\
\hline & \multirow{2}{*}{$\operatorname{High}(\geq 60 \%)$} & 10 & 9 & 17 & 36 \\
\hline & & $100 \%$ & $100 \%$ & $54.80 \%$ & $72.00 \%$ \\
\hline \multicolumn{2}{|c|}{ Chi square: $11.918 ; p<0.01$} & & & & \\
\hline
\end{tabular}

Table-4: Insight Related Factors.

\begin{tabular}{|c|c|c|c|c|c|}
\hline & \multicolumn{3}{|c|}{ Compliance (Score) } & \multirow{2}{*}{ Total } \\
\hline & & Non Compliant & Partially Compliant & Fully Compliant & \\
\hline \multirow{6}{*}{$\begin{array}{c}\text { Insight: } \\
\text { Hallucination }\end{array}$} & \multirow{2}{*}{$\begin{array}{c}\text { Low } \\
(<30 \%)\end{array}$} & 10 & 4 & 22 & 36 \\
\hline & & $100 \%$ & $44.40 \%$ & $71.00 \%$ & $72.00 \%$ \\
\hline & \multirow{2}{*}{$\begin{array}{l}\text { Medium } \\
(30-60 \%)\end{array}$} & - & 5 & 4 & 9 \\
\hline & & & $55.60 \%$ & $12.90 \%$ & $18.00 \%$ \\
\hline & \multirow{2}{*}{$\begin{array}{c}\text { High } \\
(\geq 60 \%)\end{array}$} & - & - & 5 & 5 \\
\hline & & & & $16.10 \%$ & $10.00 \%$ \\
\hline \multicolumn{6}{|c|}{ Chi square: $14.407 ; p<0.01$} \\
\hline \multirow{4}{*}{$\begin{array}{l}\text { Insight: } \\
\text { Delusion }\end{array}$} & \multirow{2}{*}{$\begin{array}{c}\text { Low } \\
(<30 \%)\end{array}$} & 10 & - & 22 & 32 \\
\hline & & $100 \%$ & & $71.00 \%$ & $64.00 \%$ \\
\hline & \multirow{2}{*}{$\begin{array}{l}\text { Medium } \\
(30-60 \%)\end{array}$} & - & 9 & 9 & 18 \\
\hline & & & $100 \%$ & $29.00 \%$ & $36.00 \%$ \\
\hline \multicolumn{6}{|c|}{ Chi square : $22.278 ; p<0.001$} \\
\hline \multirow{4}{*}{$\begin{array}{l}\text { Insight: } \\
\text { Blunt Effect }\end{array}$} & \multirow{2}{*}{$\begin{array}{c}\text { Low } \\
(<30 \%)\end{array}$} & 10 & - & 13 & 23 \\
\hline & & $100 \%$ & & $41.90 \%$ & $46.00 \%$ \\
\hline & \multirow{2}{*}{$\begin{array}{l}\text { Medium } \\
(30-60 \%)\end{array}$} & - & 9 & 18 & 27 \\
\hline & & & $100 \%$ & $58.10 \%$ & $54.00 \%$ \\
\hline \multicolumn{6}{|c|}{ Chi square: $19.612 ; p<0.001$} \\
\hline \multirow{6}{*}{$\begin{array}{l}\text { Insight: } \\
\text { Asociality }\end{array}$} & \multirow{2}{*}{$\begin{array}{c}\text { Low } \\
(<30 \%)\end{array}$} & 5 & 5 & 13 & 23 \\
\hline & & $50.00 \%$ & $55.60 \%$ & $41.90 \%$ & $46.00 \%$ \\
\hline & \multirow{2}{*}{$\begin{array}{l}\text { Medium } \\
(30-60 \%)\end{array}$} & 5 & 4 & 14 & 23 \\
\hline & & $50.00 \%$ & $44.40 \%$ & $45.20 \%$ & $46.00 \%$ \\
\hline & \multirow{2}{*}{$\operatorname{High}(\geq 60 \%)$} & - & - & 4 & 4 \\
\hline & & & & $12.90 \%$ & $8.00 \%$ \\
\hline \multicolumn{6}{|c|}{ Chi square: $2.821 ; p>0.05$} \\
\hline \multirow{4}{*}{ Total Insight } & \multirow{2}{*}{ Low $(<30 \%)$} & 10 & - & 18 & 28 \\
\hline & & $100 \%$ & & $58.10 \%$ & $56.00 \%$ \\
\hline & \multirow{2}{*}{ Medium (30-60\%) } & - & 9 & 13 & 22 \\
\hline & & & $100 \%$ & $41.90 \%$ & $44.00 \%$ \\
\hline \multicolumn{2}{|c|}{ Chi square: $19.365 ; p<0.001$} & & & & \\
\hline
\end{tabular}


Table 4 shows the relationship between insight and compliance. Comparing insight to hallucinations and compliance it was found that people with high insight are likely to be more compliant than persons with low insight, comparing insight to delusions and compliance it was found that people with high insight are likely to be more compliant than persons with low insight, comparing insight to blunt affect and compliance it was found that people with medium insight scores to blunted affect are likely to be more compliant than persons with high insight.

Table-5: Social Support Related Factors.

\begin{tabular}{|c|c|c|c|c|c|}
\hline & & $\begin{array}{c}\text { Non } \\
\text { Compliant }\end{array}$ & $\begin{array}{c}\text { Partially } \\
\text { Compliant }\end{array}$ & $\begin{array}{c}\text { Fully } \\
\text { Compliant }\end{array}$ & Total \\
\hline \multirow{4}{*}{ Significant Other } & \multirow{2}{*}{$\begin{array}{c}\text { Low } \\
(<30 \%)\end{array}$} & 10 & 9 & 23 & 42 \\
\hline & & $100 \%$ & $100 \%$ & $74.20 \%$ & $84.00 \%$ \\
\hline & \multirow{2}{*}{$\begin{array}{l}\text { Medium } \\
30-60 \%)\end{array}$} & - & - & 8 & 8 \\
\hline & & & & $25.80 \%$ & $16.00 \%$ \\
\hline \multicolumn{6}{|c|}{ Chi square $: 5.837 ; p>0.05$} \\
\hline \multirow{4}{*}{ Family } & \multirow{2}{*}{$\begin{array}{l}\text { Medium } \\
(30-60 \%)\end{array}$} & 10 & - & - & 10 \\
\hline & & $100 \%$ & & & $20.00 \%$ \\
\hline & \multirow{2}{*}{$\begin{array}{c}\text { High } \\
(\geq 60 \%)\end{array}$} & - & 9 & 31 & 40 \\
\hline & & & $100 \%$ & $100 \%$ & $80.00 \%$ \\
\hline \multicolumn{6}{|c|}{ Chi square : $50.00 ; p<0.001$} \\
\hline \multirow{6}{*}{ Friends } & \multirow{2}{*}{$\begin{array}{c}\text { Low } \\
(<30 \%)\end{array}$} & 10 & 9 & 23 & 42 \\
\hline & & $100 \%$ & $100 \%$ & $74.20 \%$ & $84.00 \%$ \\
\hline & \multirow{2}{*}{$\begin{array}{c}\text { Medium } \\
\text { 㨁30-60\%) }\end{array}$} & - & - & 4 & 4 \\
\hline & & & & $12.90 \%$ & $8.00 \%$ \\
\hline & \multirow{2}{*}{$\begin{array}{c}\text { High } \\
(\geq 60 \%)\end{array}$} & - & - & 4 & 4 \\
\hline & & & & $12.90 \%$ & $8.00 \%$ \\
\hline \multicolumn{6}{|c|}{ Chi square : $5.837 ; p>0.05$} \\
\hline \multirow{6}{*}{ Total Score } & \multirow{2}{*}{$\begin{array}{c}\text { Low } \\
(<30 \%)\end{array}$} & 5 & - & - & 5 \\
\hline & & $50.00 \%$ & & & $10.00 \%$ \\
\hline & \multirow{2}{*}{$\begin{array}{l}\text { Medium } \\
(30-60 \%)\end{array}$} & 5 & 9 & 27 & 41 \\
\hline & & $50.00 \%$ & $100 \%$ & $87.10 \%$ & $82.00 \%$ \\
\hline & \multirow{2}{*}{$\begin{array}{c}\text { High } \\
(\geq 60 \%)\end{array}$} & - & - & 4 & 4 \\
\hline & & & & $12.90 \%$ & $8.00 \%$ \\
\hline \multicolumn{2}{|c|}{ Chi square: $24.154 ; p<0.001$} & & & & \\
\hline
\end{tabular}

Table 5 shows the relationship between social support and compliance. Analysis of compliance with a social support from significant other showed no statistically significant relationships, analysis of compliance with a social support from family showed that persons with high social support from family were more compliant than persons with low social support $(\mathrm{P}<0.001)$, analysis of compliance with a social support from friends showed no statistically significant relationships, analysis of compliance with total social support showed that persons with higher social supports were likely to be more compliant than persons with low social support $(\mathrm{P}<0.001)$.

Table-6: Side effects.

\begin{tabular}{|c|c|c|c|c|c|}
\hline \multirow{4}{*}{ Psychic } & \multirow{2}{*}{$\begin{array}{c}\text { Low } \\
(<30 \%)\end{array}$} & 5 & 9 & 18 & 32 \\
\hline & & $50.00 \%$ & $100 \%$ & $58.10 \%$ & $64.00 \%$ \\
\hline & \multirow{2}{*}{$\begin{array}{l}\text { Medium } \\
(30-60 \%)\end{array}$} & 5 & - & 13 & 18 \\
\hline & & $50.00 \%$ & & $41.90 \%$ & $36.00 \%$ \\
\hline \multicolumn{2}{|c|}{ Chi square: $6.387 ; p<0.05$} & & & & \\
\hline
\end{tabular}


Table 6 shows the relationship between side effects and compliance. Analysis of psychic side effects scores showed that persons with low side effects are likely to be more compliant than persons with medium side effects scores

Table-7: Regression analysis with compliance.

\begin{tabular}{|c|c|c|c|}
\hline Parameters & B & Beta & t \\
\hline Sex & 0.502 & 0.281 & $-5.089 * *$ \\
\hline Education & 0.213 & 0.982 & $11.802^{* *}$ \\
\hline Marital Status & 1.279 & 0.98 & $15.824^{* *}$ \\
\hline Religion & 0.211 & 0.207 & 0.924 \\
\hline Occupation & 0.355 & 0.354 & $-2.259^{*}$ \\
\hline Duration of Illness & 0.922 & 0.844 & -1.744 \\
\hline Duration of Treatment & 0.783 & 0.643 & 1.194 \\
\hline Depot Preparations & 0.002 & 0.001 & -0.007 \\
\hline Drugs Administered & 0.004 & 0.361 & $-2.38 *$ \\
\hline Other Treatments & 0.205 & 0.169 & 1.239 \\
\hline * P $<0.05 ; * * \mathrm{P}<0.01$ & & \\
\hline
\end{tabular}

Regression analysis showed that Sex, Education status, marital status, Occupational status (being unemployed), and drugs administered (less number of drugs) had significant relationships with Compliance

\section{Discussions}

Comparing between age and compliance (Table 1) it was found that there was no significant relationship between age and compliance. Studies have shown that patients at the extreme ends of the age distribution have more problems adhering to treatment recommendations. Young, especially male, patients have been found to be poor compliers [15]. Elderly persons with memory deficits have reduced compliance [16].

Present study sample consisted of 14 (28\%) males and $36(72 \%)$ females analyzing the relationship between gender and compliance (Table 1) it was found that females has statistically significant compliance rates than males $(\mathrm{P}<0.05)$. Studies have shown that women tend to be more compliant than men, and younger women have been found to show better compliance than older women [17]. Findings from our study is consistent with these studies

Comparing educational status and compliance (Table 1) it was found that $28(56 \%)$ had studied up to SSLC i.e. has more than 10 years of education. We could see that compliance rates increases with number of years of education and difference was statistically highly significant $(\mathrm{P}<0.001)$ it may be explained by the fact that persons with high educational status are more aware of the benefits of medicines and that's why they take medicines.

Comparing marital status with compliance (Table 1) it was found that the group had more unmarried persons $(52 \%)$ and they had high compliance rates $(\mathrm{P}<0.001)$ the relationship was highly significant the reason could be that married persons may be living in nuclear families and the spouse going for work cannot ensure the drug compliance but unmarried usually live in extended families where someone will be there to take care of them on further analysis it was observed that unmarried has more social support compared to married $(\mathrm{P}<0.001)$.

Comparing religious status (Table 1) the group consisted mostly of Hindus (52\%) and they were found to have more compliance rates $(\mathrm{P}<0.05)$ on further analysis it was found that Hindus opt for less alternative treatments compared to Muslims and that could be a reason for their poor drug compliance.

Analysing duration of illness and compliance (Table 2) it was found that only 5 persons $(16.1 \%)$ were fully compliant in the more than 20 year illness duration category $(\mathrm{P}<0.05)$ literature reviews show that 
compliance decreases with increasing duration of illness [18] analysis of the treatment duration also showed similar results

Analyzing the relationship between expenditure of treatment and compliance (Table 2) it was found that persons who has to spent between Rs.51 and 100 has maximum compliance rates and relationship was highly significant $(\mathrm{P}<0.001)$ but on further analysis it was found that they have maximum social support and that could be the reason for increased compliance.

Analysing religious/alternate treatments and compliance (Table 2) rates it was found that people who doesn't go for alternate treatment has maximum compliance rates $(\mathrm{P}<0.05)$ it is may be concluded that alternate treatment can lead to treatment subversion.

Analysing depot preparations and compliance (Table 2) rates it was found that people who take depot has less compliance compared to people who are not on depot (P $<0.01)$. There is some evidence that managing patients with depot antipsychotics leads to higher rates of medication adherence. Young and coworkers [19] reviewed 26 studies and found a mean default rate of $25 \%$ for depot medications and $41 \%$ for oral antipsychotics. A study of patients from urban and rural environments found compliance rates exceeding 90\% for both settings. ${ }^{[20]}$ Reason could be that being on depot preparations itself is a sign of poor drug compliance and these people continue the same pattern even when they are on depot preparations.

Analysing the relationship between number of drugs administered and compliance (Table 2) it was found that persons with less number of medicines has more drug compliance then persons with more drugs ( $P$ $<0.001)$ in western studies also it was found that complexity of prescription plays a role in compliance. ${ }^{\text {[21] }}$ Patients who have complicated treatment regimenswho must take drugs at different times in the day or take two or more different medications - have less compliance.

Psychopathology and compliance- Patients who feel persecuted or are afraid to be poisoned will be reluctant to take medication. On the other hand, it is difficult to convince patients suffering from grandiose delusions or manic symptoms to comply with treatment recommendations [22]. The influence of negative symptoms in schizophrenia patients is controversial: negative symptoms have been shown to be predictors of both good [23] and bad compliance [24]. Apart from the primary illness, co morbid alcohol or substance abuse is a strong predictor of noncompliance [25-27].

Van Putten [28] identified disease features in schizophrenia that were related to poor treatment adherence and reported that patients who had pleasant delusions, particularly grandiose delusions, were more likely to refuse their medications. Severity of psychopathology can influence treatment adherence. In a study in New York, the severity of psychotic symptoms was the strongest predictor of medication noncompliance [29]. This association is supported by a study by Marder and coworkers, [30] that focused on the related issue of medication refusal. The role of impaired cognition appears to be particularly important

The relationship between positive symptoms and compliance (Table 3) showed that persons with average positive symptoms were more compliant $(\mathrm{P}<0.001)$ compared to people with low positive symptom score.

It is possible that people with more positive symptoms may take drugs to get a relief from symptoms compared to persons with low positive symptom scores.

Comparison of negative symptoms with compliance (Table 3) showed that people with average negative symptoms have more compliance rates compared to people with low negative symptom scores $(\mathrm{P}<0.05)$ negative symptoms were found to have good and bad relationship with compliance social support further analysis showed that people with average negative symptoms had more social support compared to persons with low negative symptom scores $(\mathrm{P}<.001)$.

Insight and compliance- Comparing illness insight and compliance ( Table 3) it was found that persons with low insight are more complaint compared to persons with high insight $(\mathrm{P}<0.05)$ on further analysis it was shown that persons with low insight has more social support than persons with high insight which will explain increase compliance in this group.

Pyne et al [31] found that patients who did not believe they were ill (Who had lack of insight) were more likely to be nonadherent. Adams and Scott ${ }^{[32]}$ found that patients who were noncompliant differed from compliant patients in their understanding of the severity of their illness. 
Comparing insight to hallucinations and compliance (Table 3) it was found that people with high insight are likely to be more compliant than persons with low insight $(\mathrm{P}<0.05)$ it is possible that persons with high insight take medicines because of their awareness.

Comparing insight to delusions and compliance (Table3) it was found that people with high insight are likely to be more compliant than persons with low insight $(\mathrm{P}<0.001)$ it is possible that persons with high insight take medicines because of their awareness to the delusions.

Comparing insight to blunt affect and compliance (Table 3) it was found that people with medium insight scores to blunted affect i.e. low insight are likely to be more compliant than persons with high insight $(\mathrm{P}<0.001)$ persons with a high score in a component like blunted affect (a negative symptom) are less likely to have even the motivation to take drugs.

Comparing total insight scores and compliance (Table 3) it was found that people with high insight are likely to be more compliant than persons with low insight $(\mathrm{P}<0.001)$ it is possible that persons with high insight are aware about all components of illness including disturbing hallucinations and delusions and take medicines because of their increased distress with these symptoms.

Social support and compliance- Patients who live alone generally have lower compliance rates, while patients who live in supportive environments where they have people caring for them are more likely to be compliant. ${ }^{[33]}$ An overly emotional, demanding family or significant others who do not share the patient's positive attitudes toward treatment are common examples of this problem [34].

Analysis of compliance with a social support from significant other (Table 5) showed no statistically significant relationships this finding is very significant because in west there can be a person other than a friend or family member who will be there to help the patient. But in our study such a person was not at all influential in the life of the patient highlighting the importance of family in our socio cultural background. Analysis of compliance with a social support from family (Table 5) showed that persons with high social support from family were more compliant than persons with low social support $(\mathrm{P}<0.001)$. Analysis of compliance with a social support from friends (Table 5) showed no statistically significant relationships. Analysis of compliance with total social support showed that persons with higher social supports were likely to be more compliant than persons with low social support $(\mathrm{P}<0.001)$.

Side effects- Van Putten et al [35] were the first to show that side effects that occur early in treatment lead to a substantial impairment of compliance later. An additional problem with treating schizophrenia is that most drugs have a delayed onset of action, so patients do not experience immediate positive effects. To the contrary, patients sometimes experience side effects before intended effects [35]. But other reports have failed to find significant correlations between the advent of side effects and poor compliance $[8,36]$.

Patients who experience side effects are less likely to take their medications as prescribed [37] Van Putten et al [38] and colleagues found that mild side effects, such as mild subjective akathisia, could result in poor compliance. Grunebaum et al [39] evaluated medication adherence in residential facilities. A negative view of medication-one that is likely to have been derived from side effects-was significantly related to noncompliance

Analysis of psychic side effects scores (Table 6) showed that persons with low side effects are likely to be more compliant than persons with medium side effects scores $(\mathrm{P}<0.05)$.

The overall compliance in the study was $62 \%$. Regression analysis (Table 7) showed that Age, sex, Education status, marital status, Occupation, and drugs administered had significant relationships with Compliance

\section{Limitations}

1. Cross sectional survey

2. No follow up studies were done

3. Low sample size

\section{Conclusion}

It is advisable to use minimum number of drugs for ensuring compliance.

Funding: Nil, Conflict of interest: None initiated, Permission from IRB: Yes 


\section{References}

1. Diagnostic and statistical manual of mental disorders fourth edition published by American psychiatric press, 2000 .

2. Thornley B, Adams C. Content and quality of 2000 controlled trials in schizophrenia over 50 years. BMJ. 1998 Oct 31;317(7167):1181-4.

3. Haynes RB, Sackett DL. Compliance in Health Care. Baltimore, Md: Johns Hopkins Press; 1979

4. Amador XF, Flaum M, Andreasen NC, Strauss DH, Yale SA, Clark SC, Gorman JM. Awareness of illness in schizophrenia and schizoaffective and mood disorders. Arch Gen Psychiatry.1994Oct;51(10):826-36.

5. Irwin DS, Weitzel WD, Morgan DW. Phenothiazine intake and staff attitudes. Am J Psychiatry. 1971 Jun; 127(12):1631-5.

6. Van Putten T, May PR, Marder SR. Akathisia with haloperidol and thiothixene. Arch Gen Psychiatry. 1984 Nov; 41(11):1036-9.

7. Hudson TJ, Owen RR, Thrush CR, Han X, Pyne JM, Thapa P, Sullivan G. A pilot study of barriers to medication adherence in schizophrenia. J Clin Psychiatry. 2004 Feb;65(2):211-6.

8. Fleischhacker WW, Meise U, Günther V, Kurz M. Compliance with antipsychotic drug treatment: influence of side effects. Acta Psychiatr Scand Suppl. 1994;382:11-5.

9. Cramer JA, Rosenheck R. Compliance with medication regimens for mental and physical disorders. Psychiatr Serv. 1998 Feb;49(2):196-201.

10. Fenton WS, Blyler CR, Heinssen RK. Determinants of medication compliance in schizophrenia: empirical and clinical findings.Schizophr Bull.1997;23(4):637-51.

11. Kay SR, Fiszbein A, Opler LA. The positive and negative syndrome scale (PANSS) for schizophrenia. Schizophr Bull. 1987;13(2):261-76.

12. Lingjaerde O, Ahlfors UG, Bech P, Dencker SJ, Elgen K: The UKU side effect rating scale: a new comprehensive rating scale for psychotropic drugs and a cross-sectional study of side effects in neuroleptictreated patients. Acta Psychiatr Scand Suppl. 1987, 334: $1-100$.
13. Gregory D. Zimet, Nancy W. Dahlem, Sara G. Zimet \& Gordon K. Farley. The Multidimensional Scale of Perceived Social Support. Journal of Personality Assessment.Volume 52, Issue 1, 1988, 30-41

14. Amador XF, Strauss DH, Yale SA, Flaum MM, Endicott J, Gorman JM. Assessment of insight in psychosis. Am J Psychiatry. 1993 Jun;150(6): 873-9.

15. Di Matteo MR, Di Nicola DD. Achieving Patient Compliance. New York, NY: Pergamon Press; 1982.

16. SCHWARTZ D, WANG M, ZEITZ L, GOSS ME. Medication errors made by elderly, chronically ill patients. Am J Public Health Nations Health. 1962 Dec; 52:2018-29.

17. Riecher-Rössler A. Geschlechtsunterschiede bei Schizophrenien. Presented at the 3rd Congress "Psychiatrische Erkrankungen bei Frauen"; Nov 4-6, 1999; Basel, Switzerland

18. Byerly M, Fisher R, Rush AJ, et al. A comparison of clinician vs. electronic monitoring of antipsychotic adherence in schizophrenia [poster] Presented at the 41 st annual meeting of the American College of Neuropsychopharmacology; Dec 10, 2002; San Juan, Puerto Rico.

19. Young JL, Zonana HV, Shepler L. Medication noncompliance in schizophrenia: codification and update. Bull Am Acad Psychiatry Law.1986;14(2): 105-22.

20. Docherty JP, Grogg AL, Kozma C, et al. Antipsychotic maintenance in schizophrenia: partial compliance and clinical outcome [poster]. Presented at the 41st annual meeting of the American College of Neuropsychopharmacology; Dec 8-12, 2002; San Juan, Puerto Rico

21. Eisen SA, Miller DK, Woodward RS, Spitznagel E, Przybeck TR. The effect of prescribed daily dose frequency on patient medication compliance. Arch Intern Med. 1990 Sep;150(9):1881-4.

22. Schou M. The combat of non-compliance during prophylactic lithium treatment. Acta Psychiatr Scand. 1997 May;95(5):361-3. 
23. Miner CR, Rosenthal RN, Hellerstein DJ, Muenz LR. Prediction of compliance with outpatient referral in patients with schizophrenia and psychoactive substance use disorders. Arch Gen Psychiatry. 1997 Aug; 54 (8):706-12.

24. Tattan TM, Creed FH. Negative symptoms of schizophrenia and compliance with medication. Schizophr Bull. 2001;27(1):149-55.

25. Drake RE, Osher FC, Wallach MA. Alcohol use and abuse in schizophrenia. A prospective community study. J Nerv Ment Dis. 1989 Jul;177(7):408-14.

26. Kashner TM, Rader LE, Rodell DE, et al. Family characteristics, substance abuse and hospitalization patterns of patients with schizophrenia.Hosp Community Psychiatry 1991;42:195-197.

27. Owen RR, Fischer EP, Booth BM, Cuffel BJ. Medication noncompliance and substance abuse among patients with schizophrenia. Psychiatr Serv. 1996 Aug;47(8):853-8.

28. Van Putten T. Why do schizophrenic patients refuse to take their drugs? Arch Gen Psychiatry. 1974 Jul;31(1):67-72.

29. Corriss DJ, Smith TE, Hull JW, et al. Interactive risk factors for treatment adherence in a chronic psychotic disorders population. Psychiatry Res 1999; 89:269-274

30. Marder SR, Mebane A, Chien CP, Winslade WJ, Swann E, Van Putten T. A comparison of patients who refuse and consent to neuroleptic treatment. Am J Psychiatry. 1983 Apr;140(4):470-2.
31. Pyne JM, Bean D, Sullivan G. Characteristics of patients with schizophrenia who do not believe they are mentally ill. J Nerv Ment Dis. 2001 Mar;189(3):146-53.

32. Adams J, Scott J. Predicting medication adherence in severe mental disorders. Acta Psychiatr Scand. 2000 Feb;101(2):119-24.

33. Irwin DS, Weitzel WD, Morgan DW. Phenothiazine intake and staff attitudes. Am J Psychiatry. 1971 Jun;127(12):1631-5.

34. Tamminga CA, Schulz SC. Schizophrenia Research: Advances in Neuropsychiatry and Psychopharmacology, vol 1. New York, NY: Raven Press;1991

35. Van Putten T, May PR, Marder SR. Akathisia with haloperidol and thiothixene. Arch Gen Psychiatry. 1984 Nov;41(11):1036-9.

36. Hummer M, Kemmler G, Kurz M, Kurzthaler I, Oberbauer H, Fleischhacker WW. Sexual disturbances during clozapine and haloperidol treatment for schizophrenia. Am J Psychiatry.1999 Apr;156(4):631-3.

37. Van Putten T. Why do schizophrenic patients refuse to take their drugs? Arch Gen Psychiatry. 1974 Jul; 31(1):67-72.

38. Van Putten T, May PR, Marder SR, Wittmann LA. Subjective response to antipsychotic drugs. Arch Gen Psychiatry. 1981 Feb;38(2):187-90.

39. Grunebaum MF, Weiden PJ, Olfson M. Medication supervision and adherence of persons with psychotic disorders in residential treatment settings: a pilot study [CME]. J Clin Psychiatry 2001;62:394-399.

\section{How to cite this article?}

Gopalan M.R, Vidhu Kumar K. Study of factors affecting drug compliance in schizophrenia- cross sectional survey. Int J Med Res Rev 2016;4(9):1520-1530.doi:10.17511/ijmrr.2016.i09.02. 